\title{
Morphological Aspects of the Superficial Lymph Nodes of Myrmecophaga tridactyla
}

\author{
Júlio Roquete Cardoso', Brunna Rocha Adorno ${ }^{2}$, Viviane Souza Cruz', Simone Maria Teixeira Sabóia Morais', \\ Gabriel Qualhato', Dayane Kelly Sabec Pereira ${ }^{3}$, Kleber Fernando Pereira ${ }^{4}$, \\ Paulo César Moreira' \& Marcelo Seixo de Brito e Silva'
}

\begin{abstract}
Background: The giant anteater is a Xenarthra of the Myrmecophagidae family. It is classified in Brazil as vulnerable specie, however, in Rio de Janeiro and Rio Grande do Sul it is probably extinct. In an attempt to contribute to the preservation of the species, many injured animals are referred for treatment and rehabilitation, but the lack of information about morphology may hinder a more efficient clinical-surgical approach. The knowledge on the topography, dimensions and morphology of lymph nodes of a given species is essential for medical practice. The aim of this study was to identify and describe the general morphology of the superficial lymph nodes of Myrmecophaga tridactyla.

Materials, Methods \& Results: Ten cadavers of adult Myrmecophaga tridactyla were used in this study. They were fixed and preserved with $10 \%$ formaldehyde solution and dissected throughout their length to locate their superficial lymph nodes. Lymph nodes of each center were removed for mesoscopic analysis. Measurements of width, length and thickness were obtained by a digital caliper. The superficial lymph nodes observed in the head were the mandibular and the intermandibular, while in the neck were identified superficial cervical and deep cervical lymph nodes. In the thoracic limbs, the axillary and the axillary accessory lymph nodes were present. In the pelvic limbs just one lymph node, the femoral, was observed, located in the thick subcutaneous fascia of the medial surface of the thigh. The main anatomical differences found in the lymph nodes of $M$. tridactyla are the absence of parotid, popliteal and subiliac lymph nodes and the presence of intermandibular lymph nodes and the developed femoral lymph nodes, which are unique in the pelvic limbs of this species. Moreover, some superficial lymph nodes were formed by several small lymph nodes, forming clusters, as observed in the proper and accessory axillary and femoral lymph nodes.

Discussion: The lymph nodes of the head, neck and forelimbs of the M. tridactyla followed the pattern observed in domestic animals and rats, while the morphological pattern of the lymph nodes of the head and the hindlimb differed from that described in domestic animals. Different from the dogs and ruminants where a range of superficial lymph nodes can be normally palpated, such as the mandibular; retropharyngeal; superficial cervical; subiliac; popliteal; mammary and superficial inguinal, only the femoral lymph nodes are palpable in $M$. tridactyla. The main reasons for this are the greater thickness of the skin and the absence of certain classic lymphocytes in the anteater. The peculiar anatomical features of the head and neck of M. tridactyla may have induced changes in the lymph centers of these regions when compared to the morphologic pattern of the terrestrial mammals in general. The lymph drainage of the neck, forelimbs and trunk wall was considered to be similar to that of dog, since there is equivalence of lymph nodes between these two species. The lymphatic afferents of the abdominal wall, gluteal region and hindlimbs are probably directed to the large femoral lymph nodes, which differs from domestic animals, whose lymph are mainly drained to the subiliac, ischiatic and popliteal lymph nodes. The anatomical differences related to the number, size and topography of the lymph nodes observed in M. tridactyla may be relevant in the medical procedures of this species.
\end{abstract}

Keywords: wild animals, lymph centers, lymphatic system, xenarthra.

${ }^{1}$ Department of Morphology, ${ }^{2}$ Veterinary Hospital of the School of Veterinary and Zootechny, Universidade Federal de Goiás (UFG), Goiânia, GO, Brazil. ${ }^{3}$ Laboratory of Human Anatomy, Assis Gurgacz Faculty (FAG), Cascavel, PR, Brazil. ${ }^{4}$ Laboratory of Human Anatomy, Federal University of Paraná (UFPR), Toledo, PR. CORRESPONDENCE: J.R. Cardoso [juliorcardoso@ gmail.com]. Laboratory of Animal Anatomy, UFG. Av. Esperança s/n. Campus Samambaia. CEP 74690-900 Goiânia, GO, Brazil. 


\section{INTRODUCTION}

Myrmecophaga tridactyla, popularly known as giant anteater, belongs to the superorder Xenarthra, order Pilosa and family Myrmecophagidae [17]. The superorder Xenarthra is formed by the order Cingulata, which presents osteoderms, such as armadillos, and by the order Pilosa, in which the body is covered by hair, it includes the anteaters and the sloths $[5,11,17]$. The meaning of Xenarthra is foreign joint, due to the presence of extra joints in its lumbar vertebrae to stabilize the trunk during fossorial activity [9]. This species presents very peculiar morphological and physiological characteristics among mammals, which need to be considered in clinical and surgical procedures [4], what justifies the importance of this kind of studies.

A lymph center is composed of one or more lymph nodes and its lymphatic vessels, which are responsible for the drainage of lymph from a region [13]. The anatomy of lymph nodes of domestic animals is well known $[7,10,13,14]$. However, the anatomy of these structures in wild animals were studied only in marine mammals, such as white whales [12] and dolphins [3], therefore, there is not any research concerning members of Xenarthra. Thus, the objective of this study was to identify and describe the general morphology of the superficial lymph nodes of Myrmecophaga tridactyla.

\section{MATERIALS AND METHODS}

Animals

Ten Myrmecophaga tridactyla specimens of different ages and sexes were used. The cadavers were donated by the Wild Animals Triage Center (CETAS) - IBAMA-GO. The housing, dissections and processing of the material occurred at the Institute of Biological Sciences (ICB) of the UFG.

\section{Anatomical technique}

The animals were fixed by injection of $10 \%$ formaldehyde solution into the descending thoracic aorta, plus additional injections into the body cavities and muscles. After fixation, the animals were put in formaldehyde tanks at the same concentration of the fixative solution. For the dissection of the superficial lymph nodes of the cadavers, the entire tegument was removed, followed by thorough inspection and dissection of the subcutaneous tissue to identify the subcutaneous lymph nodes. Then, the deep fascia was removed, initially in search of the usual lymph center and, later, other regions, in search of other possible lymph nodes. All procedures were performed on both antimeres.

Once a lymph center was located, it was carefully dissected and photographed, to describe the topography, neighboring structures such as muscles, blood vessels and nerves that were considered for anatomical reference, as well as the establishment of skeletopy and holotopy of the structures. The lymph nodes of each center were removed for mesoscopic analysis. Measurements of width, length and thickness were obtained by a digital caliper with resolution 0.01 $\mathrm{mm} / .0005$. Results were documented using schematic drawings and photographs taken with a Canon DSLR EOS Rebel T6i digital camera.

Descriptive statistics were used to present the results, as average (lymph nodes dimension) and percentage (frequency of the same ones).

\section{RESULTS}

The superficial lymph nodes found in the head of Myrmecophaga tridactyla were the mandibular and intermandibular ones; the parotid lymph node was absent. The mandibular lymph center was present in $100 \%$ of the animals, presenting from one to five lymph nodes in each antimere, measuring from 0.8 to $2.4 \mathrm{~cm}$ in length and 0.7 to $2.0 \mathrm{~cm}$ in width each. It extended from the caudal border of the parotid gland, from which it was separated by the facial nerve, to the ventral margin of the apex of the mandibular gland, which in this species extends from the neck to the thorax. It is associated with the maxillary vein ventrally and the linguofacial trunk superficially (Figures 1 and 4).

The intermandibular lymph center was present in $50 \%$ of the animals, presenting from one to three lymph nodes in each antimer, measuring from 0.7 to $2.2 \mathrm{~cm}$ in length and 0.3 to $0.8 \mathrm{~cm}$ in width each. They were located near the insertion of the mylohyoid muscle, along the bodies of the mandibles, in a distribution starting from a perpendicular line that crosses the center of the orbit to about $4.0 \mathrm{~cm}$ rostrally to it (Figures 2 and 4).

The dimensions of Myrmecophaga tridactyla lymph nodes are summarized in Table 1.

Superficial and deep cervical lymph nodes were found in the neck (Figure 4). The superficial cervical lymph node was present in $100 \%$ of the cadavers, being composed by a single small lymph node 
of 0.8 to $1.5 \mathrm{~cm}$ in length and 0.5 to $1.0 \mathrm{~cm}$ in width. It was located deep to the omotransverse muscle, about $3 \mathrm{~cm}$ dorsal and cranial to the scapulohumeral joint. Deep cervical lymph nodes were present in $100 \%$ of the animals, ranging from one to four lymph nodes in each antimere, measuring from 1.0 to $2.3 \mathrm{~cm}$ in length and 0.3 to $1.2 \mathrm{~cm}$ in width. The lymph nodes lied deep to the sternocephalic muscle and were associated with the carotid sheath.

In the forelimbs, the proper and accessory axillary lymph nodes were observed (Figures 3 and 4). The proper axillary lymph node was present in $100 \%$ of the specimens. It was located underneath the axillary fascia, caudally to the trunks of the brachial plexus and immediately dorsal to the pectoral muscles at the level of the second to fourth intercostal spaces. It was deeply associated with the external thoracic artery and vein and lateral thoracic nerve. It was formed by several small clustered lymph nodes united by connective tissue, giving the lymph center a lobed aspect. It was 4.0 to $7.4 \mathrm{~cm}$ long and 1.0 to $1.9 \mathrm{~cm}$ wide.

The accessory axillary lymph node (Figures $3 \mathrm{~A}$ and 4) was present in $75 \%$ and $50 \%$ of the cadavers in the right and left antimeres, respectively. Like the proper axillary lymph node, it was formed by several small lymph nodes united by connective tissue. The cluster presented between 2.7 and $4.5 \mathrm{~cm}$ in length and 1.2 to $1.4 \mathrm{~cm}$ in width. It was found caudally to the proper axillary lymph node, between the fourth and sixth ribs. In cases where the accessory axillary lymph node was absent, the proper axillary lymph node had larger dimensions.

In the hindlimbs a single large lymph node was observed, being classified here as femoral lymph node (Figures 3B and 4). It is in the thick subcutaneous tissue of the medial aspect of the thigh, at the level of the femoral triangle, medial to the gracilis muscle. It consisted of several small lymph nodes and it was present in $100 \%$ of the cadavers. The cluster measured from 6.0 to $10.5 \mathrm{~cm}$ in length by 1.26 to $1.96 \mathrm{~cm}$ in width.

\section{DISCUSSION}

Some Myrmecophaga tridactyla superficial lymph nodes were formed by several small lymph nodes, forming clusters, as in the proper and accessory axillary lymph nodes, and femoral lymph node. This finding coincides with the descriptions of equine superficial mandibular and femoral lymph nodes [7,14], but the functional significance of this lymph center composition is not reported.

In all identified lymph nodes, large variations were observed in its dimension, which is reported as a result of exposures to various antigens throughout life, causing lymphadenopathies [2].

The morphological pattern of the lymph nodes of the head of $M$. tridactyla differs from that described in domestic animals [7,13], because of the absence of the parotid and retropharyngeal lymph nodes, as well as by the presence of a group of lymph nodes defined here as intermandibular, due to its topography. The presence of lymph nodes along the intermandibular space may be related with the elongated form of the skull and face of M. tridactyla, thus requiring the presence of lymph nodes more rostrally. On the other hand, the absence of the parotid lymph node can be justified by some anatomical peculiarities, such as the poorly developed masticatory musculature, the small orbits and external ears and the proportionally small parotid gland, structures normally drained by this lymph node in other species [14]. In addition, although

Table 1. Dimensions of the superficial lymph nodes of Myrmecophaga tridactyla.

\begin{tabular}{ccccccc}
\hline & \multicolumn{3}{c}{ Left } & \multicolumn{3}{c}{ Right } \\
\hline Lymph nodes & $\mathrm{L}$ & $\mathrm{W}$ & $\mathrm{T}$ & $\mathrm{L}$ & $\mathrm{W}$ & $\mathrm{T}$ \\
Mandibular & 1.6 & 0.81 & 0.45 & 1.61 & 1.06 & 0.23 \\
Intermandibular & 1.6 & 0.4 & 0.26 & 1.23 & 0.53 & 0.13 \\
Deep Cervical & 1.1 & 0.6 & 0.3 & 1.27 & 0.77 & 0.42 \\
Superficial Cervical & 1.71 & 0.66 & 0.38 & 1.54 & 0.54 & 0.24 \\
Proper Axillary & 6.66 & 1.13 & 0.68 & 4.86 & 1.56 & 0.7 \\
Accessory Axillary & 4.5 & 1.2 & 0.5 & 3.76 & 1.3 & 0.4 \\
Femoral & 8.62 & 1.63 & 0.6 & 8.62 & 1.58 & 0.3 \\
\hline
\end{tabular}

L: length; W: width; T: thickness. Dimensions= average in $\mathrm{cm}$. 


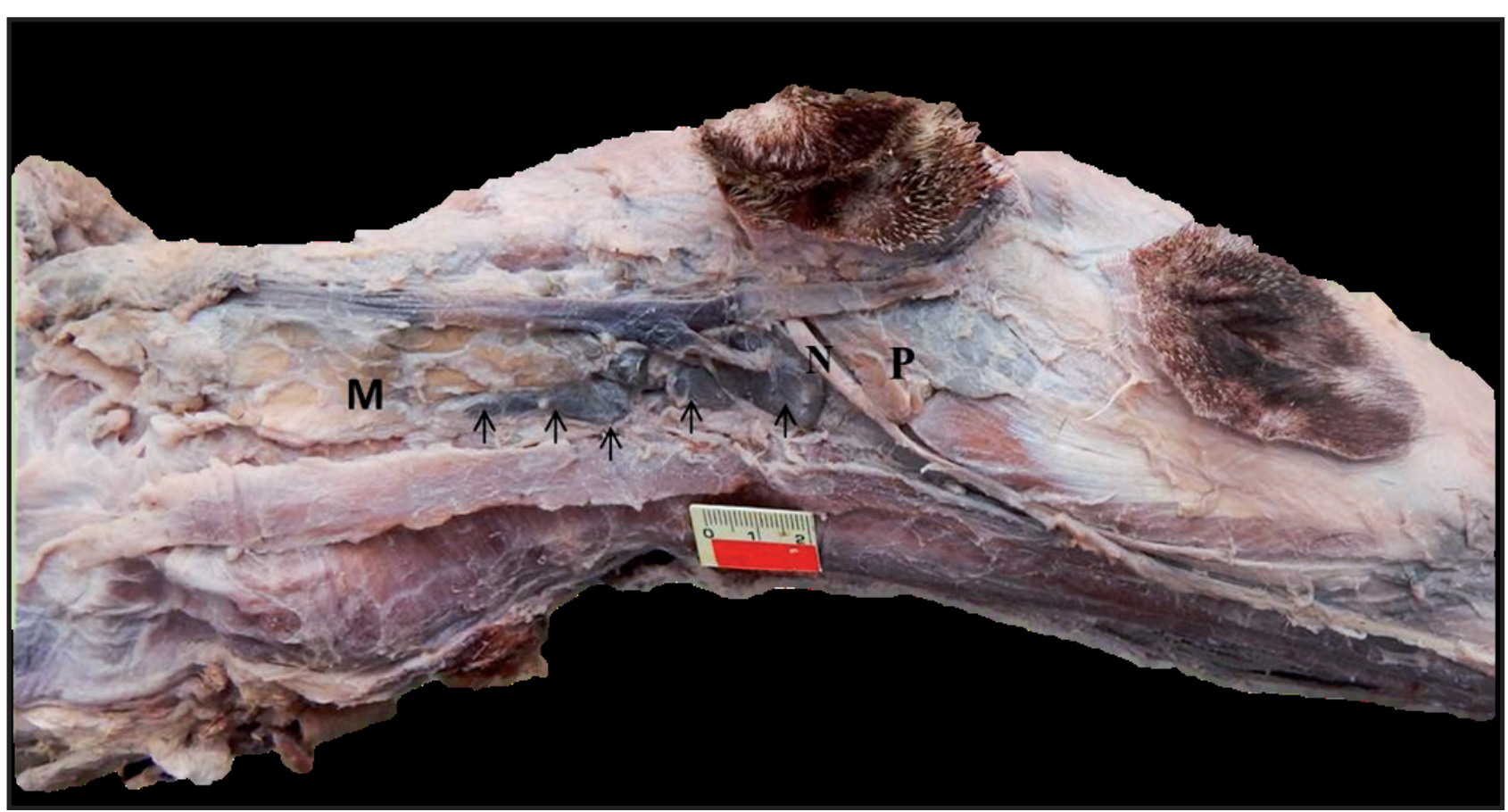

Figure 1. Right lateral view of the neck and head of Myrmecophaga tridactyla. Mandibular lymph center (arrow). N- Facial nerve; P- Parotid gland; M- Mandibular gland.

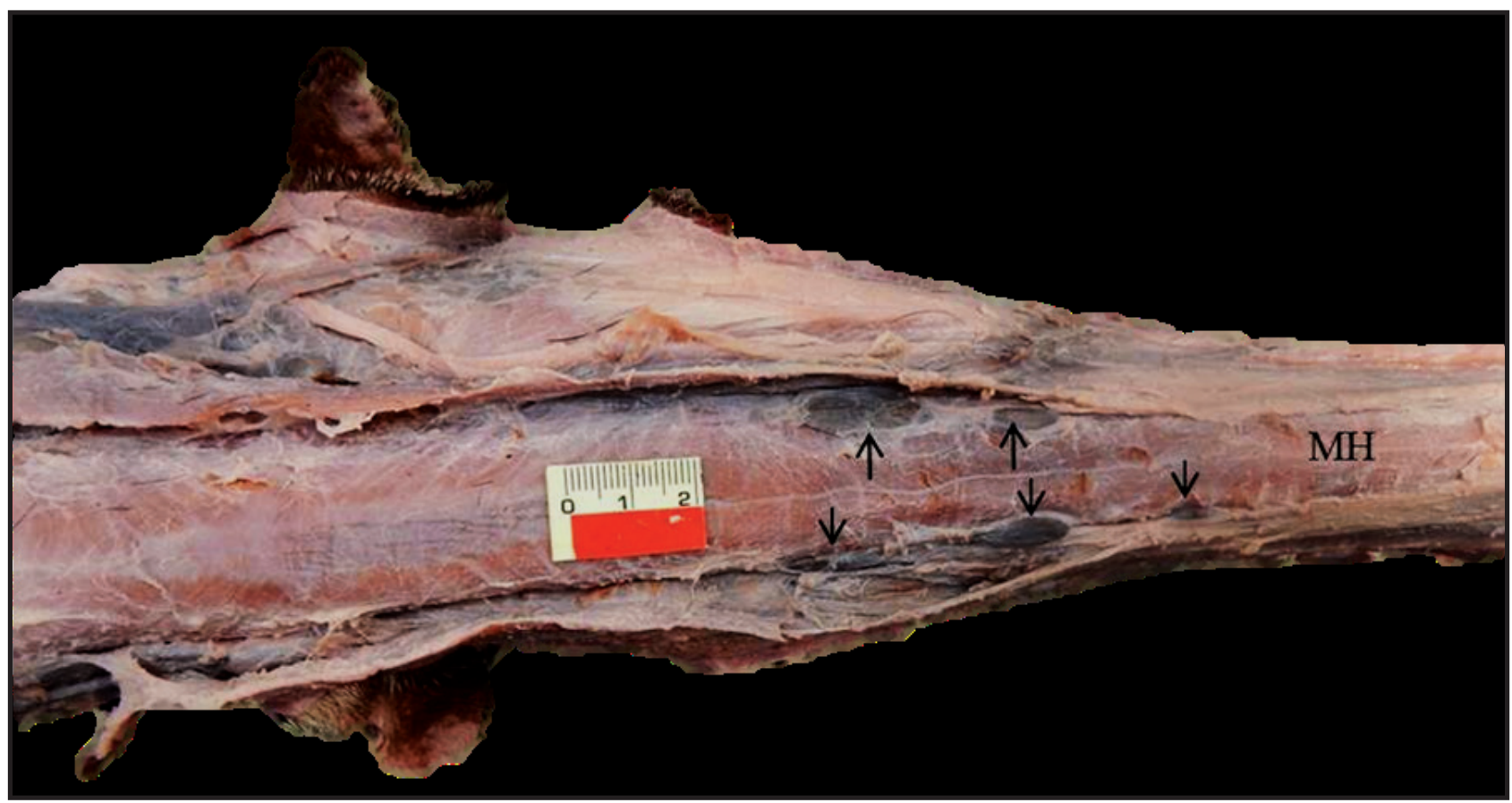

Figure 2. Ventral view of the neck and head of Myrmecophaga tridactyla showing the intermandibular lymph node (arrows) next to the insertion of the mylohyoid muscles $(\mathrm{MH})$ in the bodies of the mandibles.

the mandible gland, also called the submaxillary gland $[1,15]$, is extremely developed, it is not located in the head but rather along the neck up to the sternum.

Due to the lack of an official term [8], the name intermandibular lymph node was used, based on its topography. The classification as accessory mandibular lymph nodes would not be appropriate in this case, because in the species in which they are present, they are more closely associated with the mandibular lymph nodes, in a caudal position to them [14].

On the other hand, the lymph nodes of the head, neck and forelimbs of the $M$. tridactyla followed the pattern observed in domestic animals [13] and rats [16], being present the superficial and deep cervical lymph nodes in the neck and proper axillary and accessory axillaries in the forelimbs. 


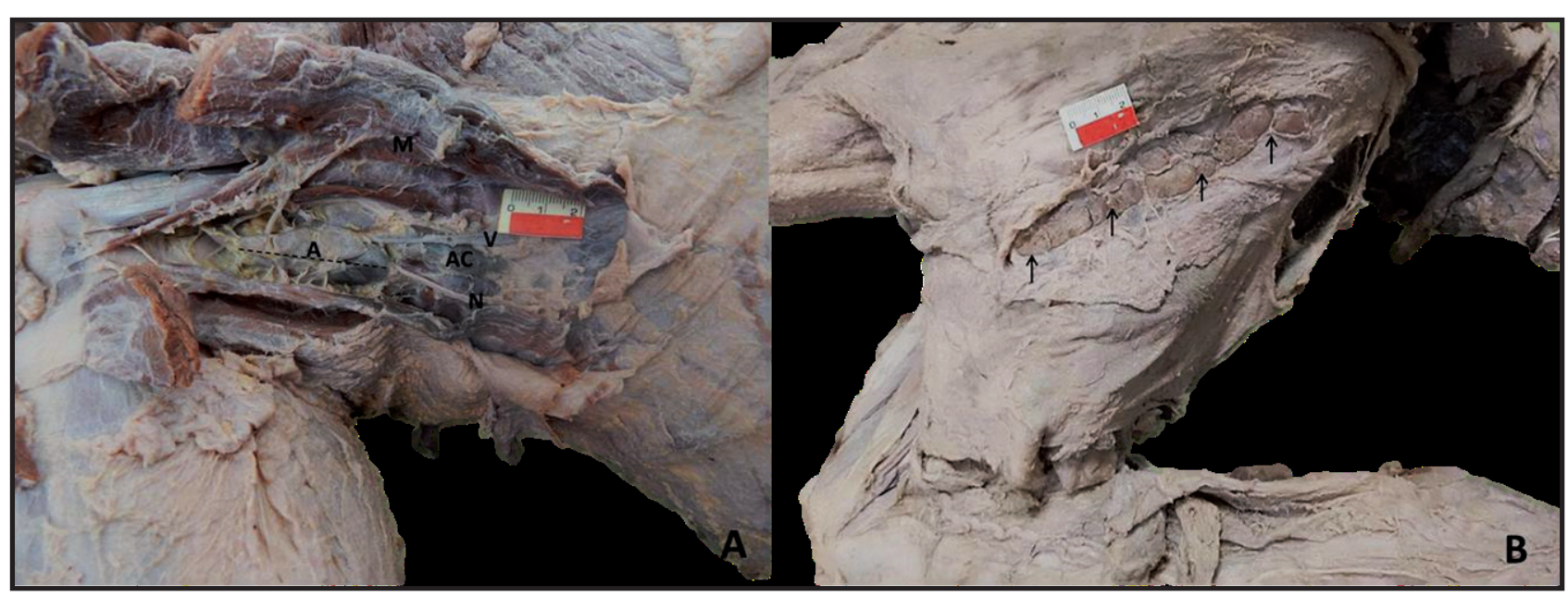

Figure 3. Lymph nodes dissected in Myrmecophaga tridactyla. A. Axillary and right lateral thoracic regions demonstrating the proper axillary lymph node (A) with its boundaries defined by dashed lines and accessory axillary lymph node (AC). M- Refuted pectoral muscles; N- Lateral thoracic nerve; V- External thoracic vein; B- Medial aspect of the right thigh presenting the femoral lymph node (arrows).

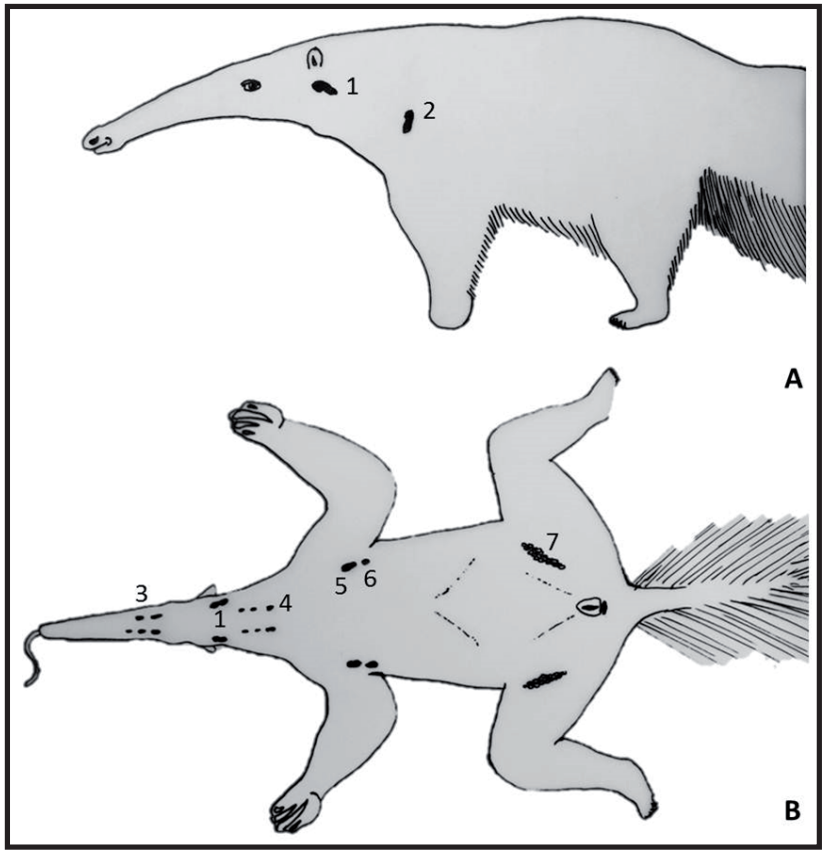

Figure 4. Schematized lateral (A) and ventral (B) view of Myrmecophaga tridactyla, displaying its superficial lymph nodes. 1- Mandibular lymph nodes; 2- Superficial cervical lymph nodes; 3- Intermandibular lymph nodes; 4- Deep cervical lymph nodes; 5 - Accessory axillary lymph nodes; 6- Accessory axillary lymph nodes; 7- Femoral lymph node.

The location of the lymph node responsible for the lymph drainage of the hindlimb of $M$. tridactyla differs from the general pattern in mammals. The only lymph node with similar topography is the femoral lymph node present in dogs. In this species, the lymph node is small, inconstant and located in the distal portion of the femoral canal $[8,13,14]$. Despite being the largest lymph node of $M$. tridactyla and the only one of the hindlimb, the topographic correspondence with dogs was considered as reference to the attribution of its terminology.
Due to its proximity to the inguinal region, the femoral lymph node of $M$. tridactyla could inadvertently be confused with the superficial inguinal lymph node, but the dissections ensured its location in the hindlimb, including its association to the medial saphenous artery and vein, while the inguinal lymph nodes are associated with the superficial caudal epigastric vessels [14]. The absence of inguinal lymph nodes in $M$. tridactyla can be partly justified not only by the size and proximity of the femoral lymph nodes but also by the fact that the anteaters do not have inguinal breasts and scrotum, structures normally drained by these lymph nodes in other species [7]. Interestingly, the popliteal lymph nodes (superficial or deep) present in all farm animals [8] and rats [16] were not evidenced in M.tridactyla. In addition, the sub iliac and ischiatic lymph nodes were absent, as in dogs [13].

A well-grounded study of the drainage area of lymph nodes requires the use of in vivo techniques, with euthanasia and dissection of the animals after injection of dyes $[2,16]$. Therefore, the present study with carcasses was restricted to estimate the lymph nodes drainage territory based on their topography. The lymph drainage of the neck, forelimbs and trunk wall was considered to be similar to that of dogs, described by Schummer et al. (1981), since there is equivalence of lymph nodes between these two species. However, an exception should be considered, since the mandibular gland of the anteater extends along the neck and therefore must be drained by the cervical lymph nodes. The lymphatic afferents of the abdominal wall, gluteal region and hindlimbs are probably directed to the large femoral lymph nodes, which differs from domestic 
animals, whose lymph are mainly drained to the sub iliac, ischiatic and popliteal lymph nodes [7,10,14]. In the absence of parotid and retropharyngeal lymph nodes in $M$. tridactyla, head lymph would be destined exclusively to the intermandibular and mandibular lymph nodes.

The superficial lymph nodes that can be examined in routine procedures of domestic animals are the mandibular; retropharyngeal; superficial cervical; pre-crural (subiliac); popliteal; mammary and superficial inguinal [6]. In M. tridactyla, however, this assertion does not apply, not only due to the absence of some of these lymph nodes, but also due to its own characteristics. Among them, the larger thickness of the skin, which makes it difficult to palpate lymph nodes that are commonly palpable in other species, such as the superficial cervical and mandibular ones. As a result, in normal conditions (without adenomegaly), we consider that only the femoral lymph nodes are palpable in a clinical examination of this species. Thus, not only because of the absence of some typical lymph nodes in the M.tridactyla, as well as the difficulty to palpate the existing ones, the clinical examination of the lymph centers in this species can be considered more difficult to be practiced.

\section{CONCLUSIONS}

The anatomical differences found in the lymph nodes of the head of Myrmecophaga tridactyla, such as the presence of lymph nodes along the intermandibular space and the absence of the parotid lymph node can be justified by the morphological peculiarities of this species, such as elongated face and skull, absence of a typical masticatory system and caudal displacement of structures usually located in the head.

The presence of a large femoral lymph node replacing the typical lymph nodes of the hindlimbs of mammals stands out as an important anatomical variation that must be considered in medical procedures in wild animals.

Ethical approval. All procedures, treatments and animal care were in compliance with the Ethics Committee on the Use of Animals of the Federal University of Goiás UFG (CEUA / UFG, protocol 018/14).

Declaration of interest. The authors report no conflicts of interest. The authors alone are responsible for the content and writing of paper.

\section{REFERENCES}

1 Brainard B.M., Newton A., Hinshaw K.C. \& Klid A.M. 2008. Tracheostomy in the Giant Anteater (Myrmecophaga tridactyla). Journal of Zoo and Wildlife Medicine. 39(4): 655-658.

2 Casteleyn C.R., Breugelmans S., Simoens P. \& Van den Broeck W. 2008. Morphological and immunological characteristics of the bovine temporal lymph node and hemal node. Veterinary Immunology and Immunopathology. 126(3-4): 339-350.

3 Cowan D.F. \& Smith T.L. 1999. Morphology of the lymphoid organs of the bottlenose dolphin, Tursiops truncates. Journal of Anatomy. 194(4): 505-517.

4 Cruz V.S., Cardoso J.R., Araújo L.B.M., Souza P.R., Borges N.C. \& Araújo E.G. 2014. Aspectos anatômicos do plexo lombossacral de Myrmecophaga tridactyla (Linnaeus, 1758). Bioscience Journal. 30(1): 235-244.

5 Dawkins R. 2009. A Grande História da Evolução. São Paulo: Companhia das Letras, 792 p.

6 Feitosa F.L.F. 2014. Semiologia Veterinária: A Arte do Diagnóstico. 3.ed. São Paulo: Roca, 644p.

7 Getty R. 1986. Anatomia dos Animais Domésticos. 5.ed. Rio de Janeiro: Guanabara Koogan, 2000 p.

8 International Committee on Veterinary Gross Anatomical Nomenclature. 2012. Nomina Anatomica Veterinaria. 5th edn. Ithaca: Cornell University, 160p.

9 Jenkins F.A. 1970. Anatomy and Functions of Expanded Ribs in Certain Edentates and Primates. Journal of Mammalogy. 51(2): 288-301.

10 Konig H.E. \& Liebich H.G. 2016. Anatomia dos Animais Domésticos. 6th edn. Porto Alegre: Artmed, 824p.

11 Pough F.H., Janis C.M. \&. Heiser J.B. 2013. A Vida dos Vertebrados. 4.ed. São Paulo: Atheneu, 750p.

12 Romano T.A., Felten S.Y., Olschowka J.A. \& Felten D.L. 1993. A microscopic investigation of the lymphoid organs of the beluga, Delphinapterus leucas. Journal of morphology. 215(3): 261-287.

13 Schaller O. 1999. Nomenclatura Anatômica Veterinária Ilustrada. São Paulo: Manole, 614p. 
J.R. Cardoso, B.R. Adorno, V.S. Cruz, et al. 2019. Morphological Aspects of the Superficial Lymph Nodes of Myrmecophaga tridactyla.

14 Schummer A., Wilkens H., Vollmerhaus B. \& Habermehl K.H. 1981. The circulatory system, the skin, and the cutaneous organs of the domestic mammals. 3rd edn. Berlin: Verlag Paul Parey, 610p.

15 Sreebny L.M. \& Meyer J. 1964. Salivary glands and their secretions. New York: Macmillan Company, 77p.

16 van Den Broeck W., Derore A. \& Simoens P. 2006. Anatomy and nomenclature of murine lymph nodes: Descriptive study and nomenclatory standardization in BALB/cAnNCrl mice. Journal of Immunological Methods. 312(1-2): 12-19.

17 Wilson D.E. \& Reeder D.M. 2005. Mammals species of the world. 3rd edn. Baltimore: The John Hopkins University Press, 2142p. 